\title{
ROUSSEAU: DA PIEDADE À INDIFERENÇA
}

\author{
Zilmara de Jesus Viana de Carvalho ${ }^{1}$
}

\section{Resumo:}

A presente comunicação objetiva demonstrar que a piedade em Rousseau, muito embora seja condição de possibilidade fundamental para o estabelecimento de relações sociais mais humanas, pode se converter em condição para a desumanidade e indiferença para com o que sofre. Argumenta-se, para tanto, que ao mesmo tempo em que a imaginação, e com ela a capacidade do homem reconhecer o outro como de sua espécie, sentindo por este empatia, encontre lugar propício para seu desenvolvimento na sociedade, também revela nesse cenário, pelo aumento das luzes, que a capacidade do homem apiedar-se pode manifestar-se, por vezes, em relação aos que se afiguram como seus iguais, porém de forma muito tênue, e até inexistente, no que concerne aos que pela distância são avaliados como diferentes, sendo por isso hostilizados. Acrescente-se a isso que a exposição excessiva a determinados acontecimentos é apresentada no Emílio como contraproducente, visto conduzir à indiferença.

Palavras-chave: Rousseau. Piedade. Imaginação. Desumanidade. Indiferença.

\begin{abstract}
:
The present communication aims to demonstrate that piety in Rousseau, although it is a condition of fundamental possibility for the establishment of more humane social relations, can become a condition for inhumanity and indifference to the suffering. It is argued, therefore, that while the imagination, and with it the capacity of man to recognize the other as his species, feeling for this empathy, finds a place conducive to its development in society, also reveals in this scenario, by the increase of the lights, that man's capacity for pity can sometimes manifest itself in relation to those who appear to be his equal, but in a very tenuous and even non-existent way, as regards those who by distance are evaluated as different, being therefore harassed. Added to this is that excessive exposure to certain events is presented in Emilio as counterproductive, since it leads to indifference.
\end{abstract}

Keywords: Rousseau. Pity. Imagination. Inhumanity. Indifference.

\section{Introdução}

A piedade em Rousseau, muito embora seja condição de possibilidade fundamental para o estabelecimento de relações sociais mais humanas, pode se converter em condição para a desumanidade e indiferença para com o que sofre. Argumenta-se, para tanto, que ao mesmo tempo em que a imaginação, e com ela a capacidade do homem reconhecer o outro como de sua espécie, sentindo por este empatia, encontre lugar propício para seu desenvolvimento na sociedade, conforme

1 Doutora em filosofia pela Universidade de São Paulo (USP). Professora do Departamento de Filosofia da UFMA e do Programa de Pós-Graduação em Cultura e Sociedade/UFMA. Bolsista de produtividade em pesquisa da FAPEMA. E-mail: ziljesus@yahoo.com.br. 
ensina o genebrino no Ensaio sobre as línguas e no Emílio, também nesse cenário, revela, pelo aumento das paixões e comodidades oriundas ao progresso, que a capacidade do homem apiedar-se, embota-se, manifestando-se, por vezes, em relação aos que, pela proximidade do convívio, afiguram-se como seus iguais, porém de forma muito tênue, e até inexistente, no que concerne aos que pela distância são avaliados como diferentes, os quais, não raro, são inclusive hostilizados. Acrescente-se a isso que a exposição excessiva a determinados acontecimentos é apresentada no Emílio como contraproducente, visto conduzir à indiferença. Objetiva-se expor de modo detalhado, à guisa de uma melhor compreensão, essas singularidades inerentes à concepção de piedade em Rousseau, analisando, para tanto, passagens extraídas de três obras do filósofo, a saber, Discurso sobre a desigualdade, Ensaio sobre a origem das línguas e Emílio.

\section{Piedade natural, amor de si e sociabilidade no Discurso sobre a desigualdade}

Partindo de um expediente metodológico já bem conhecido entre os contratualistas, a saber, o estado de natureza, Rousseau, no Discurso sobre a origem e o fundamento da desigualdade entre os homens (1755) - $2^{\circ}$ Discurso -, promove a reconstrução racional de como o homem vivia antes da sociedade civil, a fim de demonstrar os motivos que o levaram a degenerar ao entrar nela. Sem pretender aqui refazer os passos da aludida reconstrução nos limitaremos a destacar alguns pontos que consideramos relevantes para a compreensão do que pretendemos. Nessa perspectiva, observe-se que no estado de natureza de Rousseau os homens são tidos como naturalmente iguais, além disso, não podem ser considerados nem bons nem maus, tampouco dotados de vícios ou de virtudes, pelo simples fato de não haver entre eles “qualquer espécie de relação moral, ou de deveres comuns." (ROUSSEAU, 1983a, p. 251).

Em uma crítica à Hobbes, Rousseau argumenta que os homens não podem ser tidos como naturalmente maus, só por não possuírem nenhuma ideia de bondade, ou tidos como corruptos por não conhecerem a virtude (ROUSSEAU, 1983a, p. 252). Na mesma direção, diz que "os selvagens não são maus precisamente porque não sabem o que é ser bons [...]”. (ROUSSEAU, 1983a, p. 252)

\begin{tabular}{|l|l|l|l|l|}
\hline Qenista Dialectus & Ano 8 & n. 15 & Agosto - Dezembro 2019 & p. $362-373$ \\
\hline
\end{tabular}


Entretanto, sem condescender com a ideia de um mal natural, Rousseau acaba por, sob certa medida, recuar e conceder ao homem, ainda no segundo Discurso, uma única virtude natural, a saber, a piedade. Vejamos a passagem:

\begin{abstract}
Não creio ter a temer qualquer contradição, se conferir ao homem a única virtude natural [...]. Falo da piedade, disposição conveniente a seres tão fracos e sujeitos a tantos males como somos; virtude tanto mais universal e útil ao homem quando nele precede o uso de qualquer reflexão, e tão natural que as próprias bestas às vezes dão dela alguns sinais perceptíveis. [...]

Tal é o movimento puro da natureza anterior a qualquer reflexão; tal a força da piedade natural que até os costumes mais depravados tem dificuldade em destruir, porquanto se vê todos os dias, em nossos espetáculos, emocionar-se e chorar por causa das infelicidades de um desafortunado, aquele mesmo que, se estivesse no lugar do tirano, agravaria ainda mais os tormentos de seu inimigo [...]. (ROUSSEAU, 1983a, p. 253. Grifo nosso).
\end{abstract}

As características apontadas acerca de tal virtude são dignas de uma observação mais atenta, posto que Rousseau a entende como presente em toda a espécie humana, isto é, como universal, conveniente a esta, ou seja, útil (já que somos fracos e assolados por males diversos) e anterior a toda reflexão, sendo, pois, da ordem do sentimento e não um princípio ou fundamento racional, tanto que até as bestas, como diz Rousseau, dela dão sinais.

Tal sentimento, antecedendo qualquer reflexão, antecederia também a noção de moralidade, forjada artificialmente pelos homens, entretanto, mediante a aproximação destes entre si e, portanto, mediante a constituição de um núcleo familiar primitivo, ele serviria para fundamento da moral. Não sem razão, ainda no Discurso sobre a desigualdade, diz-nos Rousseau (1983a, p. 253-254), concordando com Mandeville, que os homens seriam monstruosos apesar de toda a sua moral se a natureza lhes tivesse privado da referida piedade, tendo esta sido conferida ao homem para apoio da razão, porém, indo além deste, defende que essa virtude natural deve ser, inclusive, o fundamento da moralidade, de modo que todas as virtudes sociais, como generosidade, clemência, humanidade e amizade, dela decorreriam.

Nessa perspectiva, no $2^{\circ}$ Discurso, Rousseau já anuncia algo que tratará de forma mais detida no Ensaio sobre a origem das línguas e no Emílio (1762), a saber, a relação entre a piedade e a vida em sociedade ou, por assim dizer, a reflexão. Ora, uma vez que esse sentimento é tratado como uma disposição natural e nos seres humanos as disposições naturais precisam de certas condições para se desenvolver, isto é, para cumprir plenamente o seu papel, o aumento das luzes liga-se indubitavelmente ao

\begin{tabular}{|c|c|c|c|c|}
\hline Q Rovista Dialectus & Ano 8 & n. 15 & Agosto - Dezembro 2019 & p. $362-373$ \\
\hline
\end{tabular}


desenvolvimento, o genebrino, bem antes de Kant, parece fortemente convencido desse fato, mesmo estando igualmente convencido de que o referido sentimento perde sua vivacidade com as luzes. Com efeito, afirma com relação à piedade, referindo-se a esta como comiseração, que "[...] não passa de um sentimento obscuro e vivo no homem selvagem, desenvolvido, mas fraco no homem civil” (ROUSSEAU, 1983a, p. 254. Grifos nossos.). Na sequência ainda acrescenta que:

A comiseração, com efeito, mostrar-se-á tanto mais enérgica quanto mais intimamente se identificar o animal espectador com o animal sofredor. Ora, é evidente que essa identificação deveu ser infinitamente mais íntima no estado de natureza do que no estado de raciocínio. (ROUSSEAU, 1983, p. 254a).

Obviamente, que Rousseau, ao afirmar, na citada passagem, que a identificação do animal espectador com o animal sofredor deve ter sido mais íntima no estado de natureza do que no de raciocínio está se referindo àquele momento do estado de natureza no qual já se havia constituído um núcleo social primitivo; em tal núcleo há, sim, um certo aumento das luzes, porém não em uma escala suficiente para ser considerado um estado de raciocínio, de forma que os homens ainda são denominados de selvagens. A forma como esse sentimento se expressa, bem como suas qualidades nesse tipo de sociedade são apontados, na passagem a seguir:

[...] a piedade representa um sentimento natural que, moderando em cada indivíduo a ação do amor de si mesmo, concorre para a conservação mútua de toda a espécie. Ela nos faz, sem reflexão, socorrer aqueles que vemos sofrer; ela, no estado de natureza, ocupa o lugar das leis, dos costumes e da virtude, com a vantagem de ninguém sentir-se tentado a desobedecer à sua doce voz; ela impedirá qualquer selvagem robusto de tirar a uma criança fraca ou a um velho enfermo a subsistência adquirida com dificuldade, desde que ele mesmo possa encontrar a sua em outra parte;[...]. Numa palavra, antes nesse sentimento natural do que nos argumentos sutis deve procurar-se a causa da repugnância que todo homem experimentaria por agir mal, mesmo independentemente das máximas da educação. (ROUSSEAU, 1983a, p. 254).

Há que se observar, que o homem é determinado por natureza não apenas pela presença da piedade, porém, além desta, por um outro sentimento originário, o amor de si, uma espécie de sentimento de autopreservação. Esses dois sentimentos operando de forma equilibrada, em sociedade, teria como consequência a conservação da espécie, pois a piedade, moderaria o amor de si, possibilitando o socorro àquele que sofre. Conforme esclarece Pissarra (2017, p. 30):

\begin{tabular}{|c|c|c|c|c|}
\hline Q Rovista Dialectus & Ano 8 & n. 15 & Agosto - Dezembro 201 & p. $362-373$ \\
\hline
\end{tabular}


Pela pitié, cada um se põe no lugar do outro, em sendo um sentimento inato, cada homem o recebeu na mesma porção, nem mais nem menos, o que lhe permite a capacidade de moderação do amor de si na direção do outro. Este, natural aos corações, é fundamental à manutenção da vida e as necessidades com que nela nos deparamos são alcançadas pelo desejo que nos move para os objetos em busca da satisfação daquelas. A não convergência dos desejos e das necessidades resulta na corrupção presente no estado de sociedade, pois não é mais o equilíbrio originário que nos move, mas a imaginação fantasiosa de novas necessidades. Para isso, o concurso das luzes se faz necessário.

Como atesta Rousseau, essa sociedade relativamente tranquila, da Idade de Ouro, não perdurou e a depravação da natureza humana progrediu em uma escala contínua. Sufocada a voz da piedade, prevaleceram os interesses próprios em detrimento dos comuns, bem como a inveja, a cobiça, a necessidade de domínio e toda sorte de desigualdades: a ingerência dos vícios em toda sua força.

Sobressaindo-se e desvinculando-se da piedade, o amor de si, agora sob a feição de amor próprio - que, diante dessa nova configuração, é melhor definido como egoísmo -, engendra nas relações, que a partir daí são baseadas na ambição, na inveja, na aparência de bondade, forjada pela prudência. A consequência principal dessa preeminência do amor próprio pode ser sintetizada assim: as relações fundamentadas puramente na aparência presidiram o ocultamento e esquecimento daquilo que se é, bem como da virtude e de seu cultivo.

Afirma Rousseau (1999, p. 275), em uma passagem do Emílio, que:

O amor de si, que só a nós mesmos considera, fica contente quando nossas verdadeiras necessidades são satisfeitas, mas o amor-próprio, que se compara, nunca está contente e nem poderia estar, pois esse sentimento, preferindo-nos aos outros, também exige que os outros prefiram-nos a eles, o que é impossível. Eis como as paixões doces e afetuosas nascem do amor de si, e como as paixões odientas e irascíveis nascem do amor-próprio.

Nada disso seria concebível sem o aumento das luzes. Os homens se tornaram, por meio da reflexão, não apenas desiguais, mas rivais, nascendo daí a dominação, a servidão, a violência e o roubo. Quando o amor próprio se converteu na pedra de toque de nossas decisões, o resultado é que nossas ações se dirigiram para a proteção e/ou realização de interesses próprios. Em uma passagem emblemática do Discurso sobre a desigualdade, diz Rousseau (1983, p. 254), que: “É a razão que engendra o amor-próprio e a reflexão o fortifica; faz o homem voltar-se sobre si mesmo; separa-o de quanto o perturba e aflige. [...]."

\begin{tabular}{|l|l|l|l|l|}
\hline Qenista Dialectus & Ano 8 & n. 15 & Agosto - Dezembro 2019 & p. $362-373$ \\
\hline
\end{tabular}


Observe-se que, segundo Rousseau, não é apenas o amor-próprio que se desenvolve no estado de reflexão, mas também a comiseração ou piedade, haja vista que como tivemos ocasião de citar em outro momento, é um sentimento obscuro e vivo no homem selvagem, desenvolvido, mas fraco no homem civil, dessa forma, se é bem verdade que este se torna mais fraco no estado de raciocínio, por outro lado, é igualmente verdadeiro que nesse estado ele se torna também mais desenvolvido, sofisticado, posto que raciocinamos sobre ele, tornando-o, pela razão, uma virtude e isso trás algumas vantagens para a espécie, como pode nos permitir compreender o Ensaio sobre a origem das línguas e o Emílio.

\section{Imaginação, piedade e sociabilidade no Ensaio sobre a origem das línguas e no Emilio}

Segundo Rousseau, no capítulo IX do Ensaio sobre a origem das línguas, há uma ligação íntima entre as afeições sociais e, nessa medida, entre a fraternidade e o desenvolvimento das luzes. Como os primeiros tempos teriam sido marcados pela ausência de tais laços e, por conseguinte, por fracas luzes, a força e a crueldade, oriundas do temor e da fraqueza marcariam as relações de homens que se acreditavam inimigos entre si e que, nesse sentido, estavam prontos "a fazer aos outros todo mal que neles temia." (ROUSSEAU, 1983c, p. 175).

Em linha com o disposto no $2^{\circ}$ Discurso, essa hostilidade, contudo, não é uma marca característica das relações travadas pelos primeiros homens com seus familiares, isto é, com seus semelhantes, com estes agiam de forma natural, terna e amorosa. Com efeito, como bem observou Pissarra (2017, p. 31):

A pitié não se ensina nem é aprendida, mas desperta para a alteridade, para um outro semelhante ao mesmo com o qual se identifica e no qual se reconhece. Esse foi o verdadeiro fundamento da moralidade: os homens só se reuniram em sociedade porque se reconheceram como semelhantes.

Entretanto, cumpre notar que estes homens agiam, ao mesmo tempo, de forma indiferente, desumana e feroz em relação aos que não estavam inseridos nesse universo restrito, nesse universo familiar, explica o genebrino que para tais homens "era a mesma coisa um estrangeiro, um animal, um monstro. Além de si mesmos e de sua família, todo o universo nada significava para eles.” (ROUSSEAU, 1983c, p. 175).

\begin{tabular}{|l|l|l|l|l|}
\hline Qenista Dialectus & Ano 8 & n. 15 & Agosto - Dezembro 2019 & p. $362-373$ \\
\hline
\end{tabular}


Note-se que essa amabilidade com os seus iguais não está vinculada a um conhecimento de si próprio, tampouco ao reconhecimento destes como homens, pois nesse estado de barbárie ainda não possuíam a ideia de homem. Trata-se de um estado de ignorância onde a amabilidade para com familiares e ferocidade para com os demais da sua espécie ocorria em função de que: “[...] Tudo o que conheciam lhes era caro. Inimigos do resto do mundo, que não viam e ignoravam, odiavam-se porque não podiam conhecer-se." (ROUSSEAU, 1983c, p. 176) Nessa medida, as luzes até aí desenvolvidas não eram suficientes para o reconhecimento do homem enquanto tal; ainda não há nesse estágio o que Rousseau denominou de reflexão, tampouco de imaginação. Com efeito, diz este que: "A reflexão nasce das ideias comparadas; a pluralidade dessas ideias é que leva à comparação." (ROUSSEAU, 1983c, p. 175) Ora, a reflexão advém da comparação de ideias, que, por sua vez, resulta do acionamento da imaginação. Mas quando só se tem um mesmo objeto como ter várias ideias? Com o que compará-lo? Qual a implicação disso para a piedade natural e para uma convivência social mais humanizada, menos bárbara e cruel? Rousseau (1983c, p. 175) responde no Ensaio:

\begin{abstract}
A piedade, ainda que natural ao coração do homem, permaneceria eternamente inativa sem a imaginação que a põe em ação. Como nos deixamos emocionar pela piedade? - Transportando-nos para fora de nós mesmos, identificando-nos com o sofredor. Só sofremos enquanto pensamos que ele sofre; não é em nós, mas nele, que sofremos. Figuremonos quanto de conhecimentos adquiridos supõe tal transposição. Como poderia sofrer vendo outro sofrer, se nem soubesse que ele sofre? Se ignoro o que existe de comum entre ele e mim? Aquele que nunca refletiu, não pode ser clemente, justo, ou piedoso, nem tampouco mau e vingativo. Quem nada imagina não sente mais do que a si mesmo: encontra-se só no meio do gênero humano.
\end{abstract}

É a imaginação que nos permite sair do isolamento, pois nos possibilita sair de nós e nos comparar com o sofredor, sofrendo nele a sua dor, na medida em que nos leva a refletir sobre o que há de comum entre nós e ele. Reitera Rousseau (1999, p. 289) tais afirmações, na $4^{\mathrm{a}}$ parte do Emílio, acrescentando que "ninguém se torna sensível a não ser quando a sua imaginação se excita e começa a transportá-lo para fora de si." Apenas na medida em que a sensibilidade do homem sai do plano meramente individual extendendo-se para além deste é que se pode falar em moralidade das ações, isto é, das “[...] noções do bem e do mal, que o constituem verdadeiramente como homem e parte integrante de sua espécie.” (ROUSSEAU, 1999, p. 284)

\begin{tabular}{|c|c|c|c|c|}
\hline Q Rovista Dialectus & Ano 8 & n. 15 & Agosto - Dezembro 201 & p. $362-373$ \\
\hline
\end{tabular}


Ora, muitas luzes foram necessárias para que tal passo fosse possível, de sorte que permanecendo bárbaro isso não ocorreria, a sociabilidade é, sem dúvida, o acontecimento mais importante na direção da humanização, como também na direção da decadência moral e justamente porque somente nela pode ocorrer o progresso do conhecimento. Como diz Rousseau (1983b, p. 337), no primeiro Discurso (1750): “[...] nossas almas se corromperam à medida que nossas ciências e nossas artes avançaram no sentido da perfeição." Contudo, vejamos um pouco mais sobre a vida em sociedade à luz do Emílio e não do Discurso sobre as ciências e as artes, uma vez que na primeira a relação social é tratada através da consideração de uma união que se dá em função da fraqueza do homem, concentrando-se, assim, a análise muito mais na forma como deve o homem ser instruído e na perversão que pode advir de uma má instrução e não mais a partir do recurso ao estado de natureza.

Destarte, dir-se-á da educação do adolescente, por exemplo, que: "Mostrarlhe o mundo antes que ele conheça os homens não é formá-lo, é corrompê-lo; não é instruí-lo, é enganá-lo.” (ROUSSEAU, 1999, p. 288) Pode-se, portanto, oferecer a este uma educação que lhe proporcione não apenas ver, mas imaginar o que os outros sentem, sentindo-se em seus semelhantes, comovendo-se com suas queixas e sofrendo com suas dores, trazendo "ao seu coração a primeira compaixão que jamais tenha experimentado." (ROUSSEAU, 1999, p. 288) Excitando-lhe, por conseguinte, paixões como bondade, humanidade, comiseração e impedindo "que nasçam a inveja, a cobiça, o ódio, todas as paixões repugnantes e cruéis [...]”.(ROUSSEAU, 1999, p. 289-290) Entretanto, isso que pode ser corrigido ou minimizado pela educação se desenrolará dentro de uma sociedade já constituída e corrompida, vejamos como esta é apresentada no Emílio.

Esclarece Rousseau, no Emílio, que em sociedade nasce o amor e as amizades e tais sentimentos surgem porque não somos autossuficientes, visto que dependemos e precisamos uns dos outros. Nossas misérias comuns e infelicidades nos levam a nos unir e, por assim dizer, nos levam à humanidade. Sendo assim, é por conta dos sofrimentos que nos ligamos aos nossos semelhantes, são eles que nos identificam e não os prazeres. Com efeito, diz Rousseau (1999, p. 287):

[...] nos apegamos a nossos semelhantes menos pelo sentimento de seus prazeres do que pelo de seus sofrimentos, pois vemos muito melhor nisso a identidade de nossas naturezas e as garantias de seu apego por nós. [...] O aspecto de um homem feliz inspira aos outros menos amor do que inveja;

\begin{tabular}{|c|c|c|c|c|}
\hline QRonista Dialectus & Ano 8 & n. 15 & Agosto - Dezembro 2019 & p. $362-373$ \\
\hline
\end{tabular}


[...]. Mas quem não tem pena do infeliz que vê sofrer? [...] A piedade é doce, porque ao nos colocarmos no lugar de quem sofre sentimos, no entanto, o prazer de não sofrer como ele.

Em conformidade com o disposto no Ensaio, a piedade natural é apresentada novamente como a virtude que faz com que nos coloquemos no lugar do que sofre, uma vez que através da imaginação podemos nos comparar com o sofredor e nos colocar no seu lugar, compadecendo-nos da sua dor, reconhecendo que poderíamos passar pela mesma situação, contudo ela é tratada como uma doce virtude, pois sentimos o prazer de não estar passando nós mesmos por aquele sofrimento, ou seja, nos sensibilizamos com a dor alheia, sofremos com ela, mas suspiramos aliviados por não estar acontecendo conosco, o compadecimento nos leva a acolher o que sofre, não faz com que desejemos que a mesma calamidade se abata sobre nós. Não sem razão, Rousseau (1999, p. 299), no Emílio, ao falar de seu aluno afirma que este:

\footnotetext{
Vendo de quantos males está livre, sente-se mais feliz do que julgava ser. Compartilha os sofrimentos de seus semelhantes, mas essa partilha é voluntária e doce. Goza a um só tempo da piedade que sente pelos males deles e da felicidade de não trazê-los em si. (...) Para lamentar o mal de outrem, sem dúvida é preciso conhecê-lo, mas não é preciso senti-lo.
}

A piedade ou comiseração decorre, por conseguinte, da sensibilidade sobre o que não precisamos atualmente para nós mesmos e que voluntariamente dispensamos ao que sofre, visto que estamos todos sujeitos aos sofrimentos da vida. Assim, "a comiseração deve ser um sentimento muito doce, já que depõe em nosso favor". (ROUSSEAU, 1999, p. 299).

A inveja, em contrapartida, é um sentimento amargo, pois provoca a tristeza de se não estar no lugar do que é invejado, conforme a primeira máxima formulada no Emílio: "Não pertence ao coração humano colocar-se no lugar de pessoas mais felizes do que nós, mas apenas no lugar das que estão em situação mais lastimável.”(ROUSSEAU, 1999, p. 290).

Destarte, não obstante esse doce sentimento, que é a piedade, ocorre que em sociedade também se originam os desentendimentos e ódios, curiosamente, em decorrência do amor e da amizade, isto porque a opinião dos outros passa a ter uma importância determinante na existência humana e a sociabilidade marcada por um acentuado amor próprio, possibilita a desigualdade, o domínio, o ódio, a inveja (o sentimento amargo), o conflito e toda sorte de misérias entranharem-se em seu seio.

\begin{tabular}{|c|c|c|c|c|}
\hline Q Rovista Dialectus & Ano 8 & n. 15 & Agosto - Dezembro 201 & p. $362-373$ \\
\hline
\end{tabular}


Paradoxalmente, se é a imaginação que põe em ação a piedade natural e isso só pode ocorrer no estado de raciocínio, portanto, quando a sociedade já alcançou certo nível de desenvolvimento das luzes, é justamente, também, nesse tipo de sociedade, em que se tornando alguns acontecimentos, antes tidos por impactantes, em comuns, que a imaginação humana como que perde o poder de ser impressionada, pois com a repetição contínua dos fatos nada mais causa espanto aos homens, acostumados a uma sucessão de calamidades, eles deixam de imaginar os males dos outros, logo a piedade, torna-se fraca, produzindo como consequência a impiedade e a desumanidade.

Sofrimentos e mortes perdem a capacidade de impressionar a imaginação, soma-se a isso, que só nos importamos com o sofrimento dos outros quando vemos a possibilidade de passarmos por situação semelhante, entretanto, quando a igualdade é rompida e há uma quebra nessa semelhança, resta-nos a indiferença.

\section{Desumanidade e indiferença}

No livro IV do Emílio, Rousseau, ao tratar sobre como o adolescente deve ser instruído, ao mesmo tempo que aconselha que este deva conhecer as misérias dos homens, a fim de que com estas se comova, adverte que o hábito pode torná-lo insensível a dor, de modo que não deve ser com demasiada frequência exposto a elas. Esclarece que:

[...] devemos comovê-lo, e não endurecê-lo, pela visão das misérias humanas. Impressionados durante muito tempo pelos mesmos espetáculos, deixamos de sentir suas impressões; o hábito acostuma a tudo; o que vemos demais já não imaginamos, e é somente a imaginação que nos faz sentir os males dos outros: é assim que, de tanto verem morrer e sofrer, os padres e os médicos tornam-se impiedosos. (ROUSSEAU, 1999, p. 302).

É digno de nota que no $2^{\circ}$ Discurso, considera o genebrino, que a indiferença que acaba se instaurando no coração do homem de reflexão ou, melhor dizendo, do filósofo, é tão grande, que estando ele em segurança pouco se importa com o sofrimento alheio. Nesse sentido, afirma que: "Podem impunemente degolar um seu semelhante sob sua janela, ele só terá de levar as mãos às orelhas e ponderar um pouco consigo mesmo para impedir a natureza, que nele se revolta, de identificar-se com o assassino.” (ROUSSEAU, 1983a, p. 254). Observe-se que aquele que se omite, torna-se idêntico ao que pratica a crueldade, duro e insensível. No Emílio, observa Rousseau que

\begin{tabular}{|c|c|c|c|c|}
\hline Q Rovista Dialectus & Ano 8 & n. 15 & Agosto - Dezembro 2019 & p. $362-373$ \\
\hline
\end{tabular}


"um homem duro é sempre infeliz, já que o estado de seu coração não lhe deixa nenhuma sensibilidade superabundante que ele possa conceder aos sofrimentos dos outros." (ROUSSEAU, 1999, p. 299).

Em contrapartida, aqueles que vivendo no mesmo tipo de sociedade, porém destituídos de polidez, possuem um comportamento diferente, mais ligados e identificados pelos sofrimentos e misérias comuns que lhes afligem, comportam-se de forma distinta, entregando-se "temerariamente ao primeiro sentimento de humanidade. Nos motins, nas arruaças, a populaça se reúne, o homem prudente se distancia [...]." (ROUSSEAU, 1983a, p. 254). Além disso, falta-lhes a polidez necessária para impedilos de se mostrarem como são. Diz Rousseau (1999, p. 293), no Emílio, que: “O povo mostra-se tal como é, e não é polido, mas é preciso que as pessoas do mundo se disfarcem; se se mostrassem como são, causariam horror".

Com efeito, a segunda máxima apresentada no livro IV do Emílio, afirma: "Só lamentamos no outro os males de que não nos acreditamos isentos." (ROUSSEAU, 1999, p. 291) Rousseau cita como um bom exemplo desta máxima os turcos, reconhecendo-os como mais humanos e hospitaleiros do que os europeus, cuja moral o genebrino qualifica como seca. A razão de assim considerar os turcos, diz respeito, fundamentalmente, a seu governo, descrito como "completamente arbitrário", o que acarreta àqueles que tem riquezas a clareza acerca da instabilidade dessas posses e, consequentemente, a possibilidade de perdê-las, decaindo para um estado de misérias, “cada qual pode ser amanhã o que é hoje aquele a quem ajuda." (ROUSSEAU, 1999, p. 291).

Nesse sentido, quando consideramos que de modo algum poderíamos estar suscetíveis de passar por sofrimentos análogos ao do outro, também não lamentamos sua sorte, ou seja, sua realidade não nos afeta a ponto de provocar-nos verdadeiro compadecimento e solidariedade. Pode-se inferir, sem grande dificuldade, que nas entrelinhas o que Rousseau está a dizer é que os governos europeus, gozando de certa constância em sua forma de organização, imprimiu em seus cidadãos uma segurança relativa à sua posição e condição socioeconômica, rompendo a igualdade tanto dentro da própria sociedade a qual estes pertencem (formada por ricos e plebeus, ilustrados e ignorantes), quanto fora dela. Aqui pode ser feita uma analogia com o Ensaio sobre a origem das línguas, posto que lá afirmara Rousseau, embora se referindo a Idade de Ouro, que "era a mesma coisa um estrangeiro, um animal, um monstro. Além de si

\begin{tabular}{|c|c|c|c|c|}
\hline Q Rovista Dialectus & Ano 8 & n. 15 & Agosto - Dezembro 2019 & p. $362-373$ \\
\hline
\end{tabular}


mesmos e de sua família, todo o universo nada significava para eles." (ROUSSEAU, 1983c, p. 175). De forma semelhante, no estado de raciocínio, os nobres e ricos europeus, em sua moral seca, se não conseguiam estabelecer uma relação de identificação com os miseráveis oriundos de sua própria sociedade, restando-lhes o desprezo e a indiferença, tanto menos com os estrangeiros de outros continentes (tidos como bárbaros e selvagens). Nessa perspectiva, viver em sociedade pode, facilmente, converter-se em sinônimo de desumanidade e indiferença.

\section{Referências:}

ROUSSEAU, Jean-Jacques. Discurso sobre a origem e os fundamentos da desigualdade entre os homens. $3^{\text {a }}$ ed. Tradução de Lourdes Santos Machado; Introdução e notas de Paul Arbousse-Bastide e Lourival Gomes Machado e consultoria de Marilena Chauí. In.: Os Pensadores. São Paulo: Abril Cultural, 1983a.

Discurso sobre as ciências e as artes. $3^{\mathrm{a}}$ ed. Tradução de Lourdes Santos Machado; Introdução e notas de Paul Arbousse-Bastide e Lourival Gomes Machado e consultoria de Marilena Chaú́. In.: Os Pensadores. São Paulo: Abril Cultural, 1983b.

Emílio ou da Educação. $2^{a}$ ed. Tradução de Roberto Leal Ferreira. São Paulo: Martins Fontes, 1999.

Ensaio sobre a origem das línguas. $3^{\mathrm{a}}$ ed. Tradução de Lourdes Santos Machado; Introdução e notas de Paul Arbousse-Bastide e Lourival Gomes Machado e consultoria de Marilena Chauí. In.: Os Pensadores. São Paulo: Abril Cultural, 1983c.

PISSARRA, Maria Constança P. 2017. Jean-Jacques Rousseau e a noção de pitié. Educativa. Goiânia, v. 20, n. 1, p. 24-38, jan./abr. 2017.

STAROBINSKI, J. A transparência e o obstáculo. São Paulo: Cia das Letras, 1989.

\begin{tabular}{|c|c|c|c|}
\hline Qovista Dialectus & \begin{tabular}{|l|l|} 
Ano 8 & n. 15 \\
\end{tabular} & Agosto - Dezembro 2019 & p. $362-373$ \\
\hline
\end{tabular}

